\title{
Erratum to: Mechanical behavior of the crystal lattice of natural cellulose in wood under repeated uniaxial tension stress in the fiber direction
}

\author{
Takahisa Nakai $^{1}$ - Hiroyuki Yamamoto ${ }^{2}$. \\ Tetsuya Nakao $^{1} \cdot$ Masatoshi Hamatake $^{3}$
}

\section{Erratum to: Wood Sci Technol (2006) 40:683-695 DOI 10.1007/s00226-006-0095-4}

This article was originally published in Japanese language in the Journal of the Society of Materials Science, Japan, Vol. 53, No. 4, pp. 358-363, Apr. (2004). This information was missing in the original article.

The online version of the original article can be found under doi:10.1007/s00226-006-0095-4.

\section{Takahisa Nakai}

jaja@riko.shimane-u.ac.jp

1 Shimane University, Matsue 690-8504, Japan

2 Nagoya University, Nagoya 464-8601, Japan

3 Tsuda Forest Industry, Co., Osaka 559-0025, Japan 